\title{
Menggagas Sistem Pengupahan dan Kesejahteraan Pekerja Outsourcing di Pemerintah dalam Pengadaan Publik
}

\author{
Ajik Sujoko \\ Fungsional Pengelola Barang/Jasa \\ Fakultas Hukum, Universitas Diponegoro \\ ajik.sujoko80@gmail.com
}

\begin{abstract}
Acceptance of wages and welfare of outsourcing workers in government an interesting thing to be discussed. The first, because wages and welfare in outsourcing are quite relevant issues for labor conditions. Second, through outsourcing, the government is able to accommodate outsourcing workers whose trends increase each year. Third, the government are not in the form of company, but are already used to implementing outsourcing practices. Fourth, the tendency of private participation to improve the performance of government which is profit oriented. Of the four discussions and cases of outsourcing in some places, the attractive position of outsourcing workers is always in a weak position and an uncertain future, including in government. By reviewing the practice of procurement process of government goods/services, through this article contributes and encourages to government and outsourced employers has the ability and willingness to provide wages and welfare of outsourcing workers. How wages and welfare are enjoyed and accepted by outsourcing workers, through public procurement can be done adequacy of the procurement budget, provider selection process that follows labor regulations and contracting properly with the provider
\end{abstract}

Keywords: Wages, Welfare, Outsourcing Workers, Procurement Of Goods/Services

\begin{abstract}
Abstrak
Penerimaan upah dan kesejaheteraan pekerja outsourcing di pemerintah hal yang menarik untuk didiskusikan. Yang pertama, karena upah dan kesejahteraan dalam outsourcing merupakan masalah yang cukup relevan menggambarkan kondisi tenaga kerja. Kedua, melalui outsourcing pemerintah mampu menampung pekerja outsourcing yang cenderung naik tiap tahun. Ketiga, pemerintah bukan sebuah perusahaan, namun telah biasa menggunakan praktik outsourcing. Keempat, kecenderungan partisipasi swasta untuk meningkatkan kinerja pemerintah yang berorientasi pada keuntungan. Dari empat diskusi dan kasus outsourcing di sebagian tempat, menariknya posisi pekerja outsourcing selalu dalam posisi yang lemah dan masa depan yang tidak pasti, termasuk di pemerintahan. Dengan melihat praktek proses pengadaan barang/jasa pemerintah, melalui artikel ini diharapkan memberikan kontribusi dan dorongan kepada pemerintah dan
\end{abstract}


pengusaha outsourcing memiliki kemampuan dan kemauan untuk menyediakan upah dan kesejahteraan pekerja outsourcing. Bagaimana upah dan kesejahteraan dapat dinikmati dan diterima oleh pekerja outsourcing melalui pengadaan publik, dapat dilakukan dengan menyediakan kecukupan dari anggaran pengadaan, proses pemilihan penyedia yang mengikuti peraturan ketenagakerjaan dan kontrak dengan penyedia secara benar.

Kata kunci: Upah, Kesejahteraan, Pekerja Outsourcing, Pengadaan Barang/Jasa

\section{A. Pendahuluan}

Outsourcing is not a new concept in the modern business environment.[1] Outsourcing yang biasa diterapkan dalam privat sektor telah merambah di sektor publik. Penggunaan outsourcing dalam sektor publik yang dilakukan instansi pemerintah di Indonesia muncul di era tahun 2003an, seiring dengan terbitnya peraturan pengadaan barang/jasa pemerintah. Outsourcing di pemerintah, tidak hanya menyangkut aspek ketenagakerjaan namun menyangkut aspek publik lainnya berkaitan dengan proses pengadaannya. Penggunaan outsourcing pada umumnya adalah bidang jasa layanan kebersihan, jasa layanan keamanan, driver, resepsionis dan sumber daya manusia lainya. Sebagaian besar praktik penggunaan outsourcing adalah lemahnya pemberian upah dan kesejahteraan kepada pekerja outsourcing sebagaimana dari berbagai penelitian yang ada (Ajik Sujoko[2], Angelina Londa[3], Priagung Luhur[4], Istianah Ni'mah[5]).

Meskipun praktik penggunaan outsourcing diwarnai dengan masalah ketenagakerjaan, realitanya penggunaan outsourcing di pemerintah meningkat tiap tahunnya. Hal ini bisa dilihat dari Sistem Rencana Umum Pengadaan (SIRUP) yang dibuat oleh Lembaga Kebijakan Pengadaan Pemerintah (LKPP)[6] yang menayangkan banyaknya paket pekerjaan outsourcing. One of four major economic activities; purchasing goods, services and capital assets[7], melalui outsourcing, pemerintah terbuka dan mampu menampung pekerja outsourcing. Outsourcing di pemerintah juga menjadi solusi menyediakan lapangan kerja bagi tenaga kerja. 
Penggunaan outsourcing di pemerintah cenderung meniru praktik bisnis yang biasa dilakukan oleh perusahaan. Government outsourcing is often undertaken to reduce costs and improve the quality of public services.[8] Menurut Pasal 64 Undang-Undang Republik Indonesia Nomor 13 Tahun 2003 tentang Ketenagakerjaan, perusahaan dapat menyerahkan sebagian pelaksanaan pekerjaan kepada perusahaan lainnya melalui perjanjian pemborongan pekerjaan atau penyediaan jasa pekerja/buruh yang dibuat secara tertulis. Penyerahan sebagian pelaksanaan pekerjaan ini yang biasa disebut dengan outsourcing. Jika ditanya dasar hukum penggunaan outsourcing di pemerintah, belum ada peraturan yang mengaturnya. Kendati belum ada dasar hukumnya penggunaan outsourcing di pemerintah, dalam administrasi negara pemerintah memiliki kewenangan (menggunakan freies ermessen) untuk melakukan perbuatan hukum privat dengan pihak swasta[9], agar pelayanan publik tidak terganggu. Freies ermessen ini muncul sebagai alternatif untuk mengisi kekurangan dan kelemahan di dalam penerapan asas legalitas[10]. Freies ermessen outsourcing di pemerintah merupakan inovasi dalam melimpahkan tanggung jawab kepada pihak swasta yang dilakukan melalui kontrak setelah proses pemilihan penyedia.

Pelimpahan tanggung jawab dari pemerintah kepada pihak swasta tidak hanya menguntungkan dari sisi efisiensi manajamen dan biaya. Ada peran pihak swasta yang berkompetisi, diharapkan mampu meningkatkan value for money. The principle of value for money means the effective, efficient, and economic use of resources, which requires an evaluation of relevant costs and benefits, along with an assessment of risks, and non-price attributes and/or life cycle costs, as appropriate.[11] Artinya, jasa yang diberikan pihak swasta sesuai nilai dan beban kerja yang diberikan pemerintah. Pemerintah juga diuntungkan dari sisi hukum, khusunya mengenai ketenagakerjaan, karena tidak disibukkan urusan aspek hukum mengenai pekerja outsourcing. Terbukanya peluang pelimpahan tanggung jawab memunculkan partisipasi swasta bagaimana ikut meningkatkan kinerja pemerintah dalam melayani publik. Sudah dimaklumi secara umum bahwa pihak swasta begitu rigit dalam hal menajemen dan berorientasi mencari keuntungan. 
Dari uraian di atas, dibuat bagan untuk melihat permasalahan mengenai pekerja outsourcing di pemerintah mendapatkan upah dan kesejahteraan sebagai berikut :

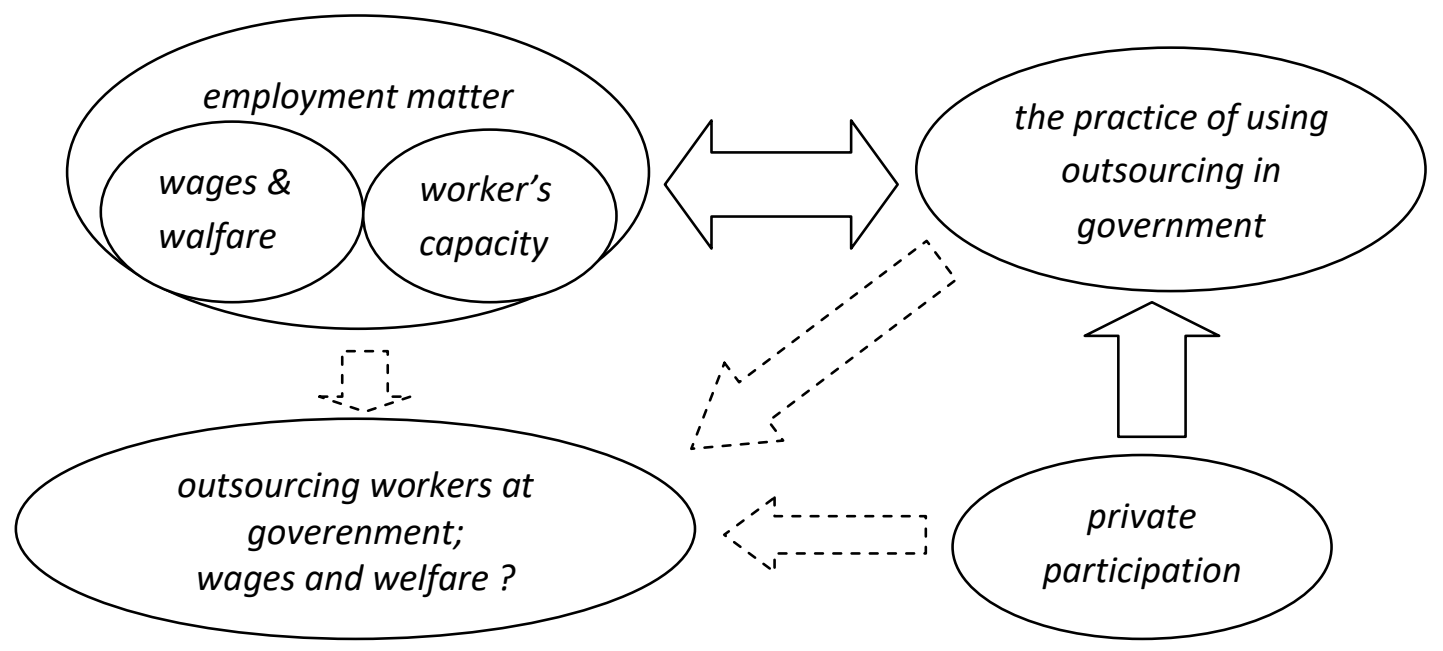

\section{B. Pembahasan}

Penerimaan upah dan kesejahteraan pekerja outsourcing di pemerintah dapat dilihat dari proses pengadaannya. Ada tiga garis besar proses pengadaan outsourcing di pemerintah yaitu, proses penganggaran, proses pemilihan penyedia dan pelaksanaan kontrak. Melalui bagan di bawah ini mencoba menguraikan proses pengadaan outsourcing di pemerintah sampai dengan penerimaan upah dan kesejahteraan pekerja outsourcing.

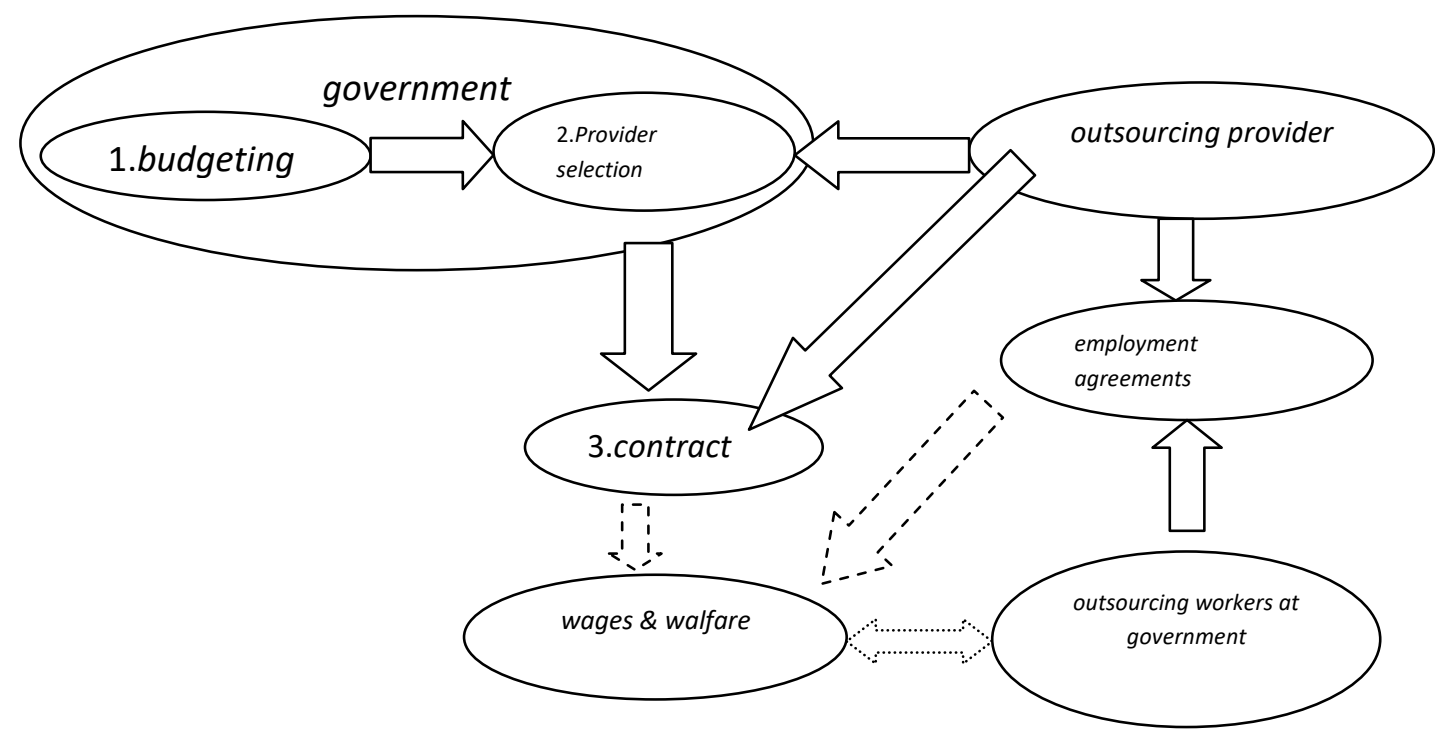




\section{Proses Penganggaran}

Anggaran dalam penggunaan outsourcing di pemerintah dimana prosesnya jalan seiringan dalam proses perencanaan, belum ada keseragaman dan belum ada ketentuan yang baku. Masalah anggaran ketersediaan atau kecukupan penggunaan outsourcing di pemerintah merupakah hal yang klasik sesuai kemampuan dan kondisi keuangan tiap-tiap instansi pemerintah. Asumsi pemerintah memiliki kecukupan dana dalam penggunaan outsourcing tidak sepenuhnya benar, karena beberapa paket pekerjaan outsourcing di pemerintah dipaksakan dilelang dengan keterbatasan anggaran.[2] Kecukupan anggaran ini digunakan untuk membayar kepada penyedia outsourcing terpilih. Anggaran pengadaan outsourcing di pemerintah memperhitungkan biaya personil atau non personil ditambah beban pajak dan keuntungan penyedia/fee manajemen.

Biaya personil digunakan untuk membayar pekerja outsourcing secara layak yaitu menerima upah dan mendapatkan kesejahteraan sesuai beban pekerjaannya. Biaya non personil digunakan untuk membiayai peralatan yang dibutuhkan dalam pelaksanaan pekerjaan. Menghitung rancana upah bagi pekerja outsourcing tidak bisa dilepaskan dari hal yang sifatnya objektif dan subjektif. Tujuannya untuk antisipasi menghindari ketidaknyamanan bagi pengguna (pihak pemerintah) maupun pekerja outsourcing dan seberapa kelayakan penerimaan upah . Objektif rencana kebutuhan pekerja outsourcing dilihat dari pengalaman atau keterampilan pekerjaan yang dibuktikan dengan ijasah atau surat keterangan keterampilan. $A$ number of studies have attempted to identify the determinants of the skilledunskilled wage gap.[12] Subjektifitas pekerja outsourcing dapat menyangkut mengenai softskill, kepribadian, gender, keberanian, cantik atau tampan, umur, tinggi badan, warna kulit dan seterusnya. Sebagai misal, penempatan pekerja outsourcing di bagian resepsionis, lebih menarik seorang pekerja yang masih muda, cantik dan terampil, ketimbang pekerja yang sudah berpengalaman namun kelihatan tua. Perencanaan kriteria pekerja outsourcing syarat akan nilai subjektif penting dilakukan, agar pekerja outsourcing terpilih bekerja dengan nyaman, seperti proses seleksi pegawai tetap atau tenaga kontrak. Kesalahan dalam penempatan pekerja outsourcing akan memberikan dampak buruk bagi pekerja 
outsourcing itu sendiri, seperti permintaan penggantian pekerja oleh pengguna. Dalam pengadaan di pemerintah meskipun tidak lepas dari hal yang sifatnya subjektif namun capaian output pekerjaan adalah yang dituju. Value for money penggunaan pekerja outsourcing bisa terjadi jika kriteria pekerja outsourcing yang dipekerjakan oleh penyedia outsourcing sesuai dengan kebutuhan pengguna dan mendapatkan upah dan kesejahteraan sesuai kriterianya.

Kelayakan anggaran besaran upah dan penerimaan kesejahteraan pekerja outsourcing dapat mengacu pada ketentuan peraturan mengenai ketenagakerjaan yang berlaku. Kelayakan upah dengan menyesuaikan Upah Minimum Regional, memiliki kelemahan tidak bisa mengcover tuntutan dari penggunaan pekerja outsourcing hal yang sifatnya subjektif. Artinya pekerja diberikan upah dan kesejahteraan yang sama tanpa memperhitungkan kelebihan yang sifatnya subjektif. Altough, conclusion that the minimum wage reduces employment of low-skilled workers is clearly incorrect[13], dalam penggunaan outsourcing di pemerintah tidak sekedar mencapai efisiensi biaya, namun juga mempertimbangkan ketentuan ketenagakerjaan. Oleh karena itu dalam penganggaran ini pentingnya memperhatikan kriteria pekerja outsourcing yang dibutuhkan agar mencerminkan tujuan value for money sejak perencanaan. Perencanaan semacam ini perlu dilakukan pemerintah ketika akan merencanakan penggunaan outsourcing.

\section{Proses Pemilihan Penyedia}

Tujuan utama pemilihan penyedia outsourcing adalah mendapatkan penyedia outsourcing yang mampu melaksanakan pekerjaan dan berkompeten di bidangnya. Pemilihan penyedia outsourcing di pemerintah masuk lingkup public procurement. Public procurement is subject to special rules in order to secure that goods and services are acquired at competitive prices. Similar to other systems, the public procurement system's ability to accomplish procurement policies/goals is influenced by its environment. Influencing the public procurement system includes many types: market, internal environment, legal environment, political environment, and socio-economic and other environment.[7] In many countries, public procurements are regulated by formal 
rules and regulations.[7] Clear regulations have dominated public procurement, underpinning the advantages of tendering as the main form of purchasing goods and services within the sector.[14] When managed effectively, public procurement improves service delivery, supports the achievement of strategic objectives, and delivers savings and benefits to the community.[15]

Pelaksana pemilihan penyedia outsourcing dipemerintah dilakukan oleh suatu organisasi atau agen pemerintah yang bertugas memilih penyedia. Agen ini biasa disebut Unit Layanan Pengadaan atau sebutan lain yang menggambarkan tugas dan fungsi pengadaan pemerintah. The procurement agents are supposed to ensure that the interests of the state and the public, as well as the legal rights of all participants in a bidding activity, are protected.[16]

Melalui tender, agen melaksanakan pemilihan penyedia. Penyedia outsourcing merupakan perusahaan yang merekrut pekerja dan menyuplai pekerja yang diminta sesuai permintaan. Perekrutan pekerja oleh penyedia outsourcing berorientasi agar pekerja memberikan kontribusi kepada perusahaan dengan memperlihatkan produktivitas kerja pada pengguna jasa. Orientasi perekrutan semacam ini dapat dilakukan melalui pasar kerja. Empirically show that increased labor market flexibility increases labor productivity.[17]

Dalam proses tender, selecting a supplier without a competitive bidding mechanism should raise concerns regarding transparency and more importantly, avoiding favoritism and outright corruption.[18] The evidence of a positive impact of the level of competition on the difference between the expected the need for public authorities to use the open procedure involving a sufficient number of applicants as a primary option.[19] Di dalam tender tidak sepenuhnya proses tawar menawar berjalan mulus. Balancing the efficiency and cost-effectiveness on the one hand and innovation on the other hand often leads to situations of conflict. Regulations and control mechanisms in public procurement limit buyers' freedom of action. While private sector investments in innovation sometimes follow "trial-and-error" patterns.[20]

Hasil dari pemilihan penyedia yang berorentasi pada efektivitas biaya tidak sepenuhnya dapat menjamin pemberian upah dan kesejahteraan secara layak 
kepada pekerja outsourcing. Terlebih lagi dalam sistem evaluasi dalam tender menggunakan sistem gugur, sangat rentan penawaran terendah dari penyedia yang berpeluang menjadi pemenang. Harga terendah tidak bisa dianggap mencerminkan konsep value for money dalam pengadaan, karena harus dibuktikan dalam kualitas hasil pekerjaan. Oleh karena itu dalam dokumen tender sebagai dasar aturan main tawar menawar, perlu dipertegaskan kesanggupan penyedia outsourcing memberikan jaminan upah dan kesejahteraan yang layak kepada pekerja outsourcing minimal sesuai peraturan perundang-undnagan dibidang ketenagakerjaan.

\section{Kontrak Dengan Penyedia}

Kontrak pekerjaan outsourcing di pemerintah dengan pihak swasta tidak sekedar masuk dalam hukum privat, namun juga masuk dalam hukum publik. Inti hubungan kontraktual menurut Parsons adalah "free agreement of individuals".[21] Kebebasan berkontrak dalam pengadaan di pemerintah tidak sepenuhnya benar karena pihak pemerintah lebih diuntungkan karena kontrak dibuat oleh pihak pemerintah sejak draft sampai dengan ditandatangani. The contract type should be determined[8], dimana masuk dalam proses kompetisi atau tender. Kontrak yang ditandatangani penyedia merupakan skema dari draft kontrak yang dibuat oleh pemerintah.

Jangka waktu kontrak pekerjaan outsourcing antara pemerintah dengan penyedia outsourcing terdiri dari jangka pendek dan jangka panjang. Jangka pendek kontrak outsourcing tidak melebihi satu tahun anggaran, sedangkan jangka panjang bisa multi years. Short-term outsourcing contracts tend to target employment terms and working conditions with a cost factor to be minimized while long-term outsourcing agreements based on partnership are aimed at promoting good employment relations and best practice approach to staff management.[22]

Kontrak pekerjaan outsourcing antara pemerintah dan penyedia tidak sepenuhnya menjamin besaran upah dan kesejahteraan yang diterima pekerja outsourcing sesuai penawaran. Selain penyedia berkontrak dengan pihak pemerintah, ia juga mengadakan perjanjian kerja dengan pekerja outsourcing. 
Dalam perjanjian kerja inilah hak dan kewajiban antara pekerja outsourcing dengan penyedia dijelaskan, termasuk di dalamnya mengenai upah dan kesejahteraan. Munculnya kasus pengurangan upah yang diterima pekerja outsourcing, point utamanya karena sudah ditentukan dalam perjanjian kerja antara pekerja outsourcing dengan penyedia. Oleh karena itu bagaimana membuat kontrak pekerjaan outsourcing di pemerintah dengan benar perlu dilakukan dengan memperhatikan point utama sebagai berikut:

a) Dapat mengalihkan resiko yang ditanggung pemerintah kepada pihak penyedia, termasuk resiko tuntutan hukum yang berkaitan dengan ketenagakerjaan.

b) Menjamin upah dan kesejahteraan yang diterima pekerja outsourcing yang diikat dalam kontrak dan perjanjian kerja.

c) Mencerminkan value for money antara nilai kontrak dengan hasil pekerjaan (bukan efisisensi biaya hasil tender).

d) Resolving case of a dispute and where the dispute will be decided.[23]

Kontrak yang dilakukan dengan melihat pengalihan resiko, jaminan upah dan kesehateraan, value for money, dan pemecahan masalah diharapakan dapat menjamin besaran upah dan kesejahteraan yang diterima pekerja outsourcing.

\section{KESIMPULAN}

Upah dan kesejahteraan dapat dinikmati dan diterima oleh pekerja outsourcing melalui pengadaan publik, dapat dilakukan dengan menyediakan kecukupan dari anggaran pengadaan, proses pemilihan penyedia yang mengikuti peraturan ketenagakerjaan dan kontrak dengan penyedia secara benar.

\section{Daftar Pustaka}

[1] A. Vaxevanou and N. Konstantopoulos, "Basic Principles the Philosophy of Outsourcing," Procedia - Soc. Behav. Sci., vol. 175, pp. 567-571, 2015.

[2] A. Sujoko, "Upaya Meningkatkan Upah dan Kesejahteraan Pekerja Outsourcing di Universitas Diponegoro melalui Pengadaan Barang/Jasa Pemerintah," Semarang, 2018.

[3] A. Londa, "Konstruksi Sosial Pekerjaan Outsourcing Di Kalangan Buruh Pertambangan Di Bontang," J. Penelit., 2016. 
[4] P. Luhur, "Analisis Kesejahteraan Tenaga Kerja Outsourcing Dalam Perspektif Ekonomi Islam (Studi Kasus Pada Tenaga Kerja Outsourcing CV. Amara di IAIN Purwokerto)," Institut Agama Islam Negeri Purwokerto, 2016.

[5] I. Ni'mah, “Analisis Kesejahteraan Karyawan Outsourcing Dalam Perspektif Karyawan PT Spirit Krida Indonesia," J. Ekon. Syariah, vol. 4, no. 2, pp. 300-317, 2016.

[6] Lembaga Kebijakan Pengadaan Barang/Jasa, "SiRUP.” [Online]. Available: https://sirup.lkpp.go.id/sirup/.

[7] K. V. Thai, "PUBLIC PROCUREMENT RE-EXAMINED," J. Public Procure., vol. 1, no. 1, pp. 9-50, 2001.

[8] School of Public and Environmental Affairs, "Government outsourcing: A Practical Guide for State and Local Governments," 2014.

[9] A. Sujoko, "Outsourcing jasa kebersihan di instansi pemerintah," Masal. Masal. Huk., vol. 46, no. 4, pp. 369-376, 2017.

[10] G. A. R. Damayanti, "Freies Ermessen Dalam Konsep Negara Kesejahteraan," vol. 6, no. 1, pp. 41-48, 2016.

[11] I. IBRD, "Bank Policy Procurement in IPF and Other Operational Procurement Matters," vol. OPSVP5.05, no. November 7, 2017, p. 3.

[12] S. Anwar, "Outsourcing and the skilled-unskilled wage gap," Econ. Lett., vol. 118, no. 2, pp. 347-350, 2013.

[13] D. Neumark and W. L. Wascher, "Minimum Wages and Employment," Found. Trends® Microeconomics, vol. 3, no. 1-2, pp. 1-182, 2006.

[14] J. Stentoft Arlbjørn and P. Vagn Freytag, "Public procurement vs private purchasing," Int. J. Public Sect. Manag., vol. 25, no. 3, pp. 203-220, 2012.

[15] V. Auditor-general, "Tendering and Contracting in Local Government," 2010.

[16] Asian Development Bank, Outsourcing Procurement in the Public Sector. 2013.

[17] C. M. Bjuggren, "Employment protection and labor productivity," J. Public Econ., vol. 157, pp. 138-157, Jan. 2018.

[18] S. Tadelis, "Public procurement design: Lessons from the private sector," Int. J. Ind. Organ., vol. 30, no. 3, pp. 297-302, May 2012.

[19] T. Hanák and P. Muchová, "Impact of Competition on Prices in Public Sector Procurement," Procedia Comput. Sci., vol. 64, pp. 729-735, Jan. 2015.

[20] N. Obwegeser and S. D. Müller, "Innovation and public procurement: Terminology, concepts, and applications," Technovation, no. April 2016, pp. 1-17, 2018.

[21] A. Saleng, "Hubungan Hukum antara Pemerintah dengan Badan Usaha Swasta dalam Berbagai Pola Kontrak Kerjasama Pengusahaan Pertambangan," J. Huk., vol. 7, no. 13, pp. 12-30, 2000.

[22] L. Gaspareniene and J. Vasauskaite, "Analysis of the Criterions of Outsourcing Contracts in Public and Private Sectors: Review of the Scientific Literature," Procedia - Soc. Behav. Sci., vol. 156, pp. 274-279, 
\begin{tabular}{l|l} 
Adminitrative Law \& Governance Journal Vol. 1 Edisi 4 Nov 2018 & ISSN 2621 - 2781 Online
\end{tabular}

Nov. 2014.

[23] "Employment contracts," Dent. Abstr., vol. 63, no. 1, pp. 6-7, Jan. 2018. 